\title{
The post-nuclear accident co-expertise experience of the Suetsugi community in Fukushima Prefecture
}

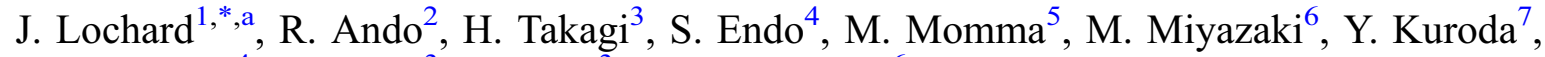 \\ T. Kusumoto ${ }^{4}$, M. Endo ${ }^{3}$, S. Endo ${ }^{3}$ and Y. Koyama ${ }^{6}$ \\ ${ }^{1}$ Nagasaki University, Atomic Bomb Disease Institute, Nagasaki, Japan. \\ 2 Ethos in Fukushima, Iwaki, Fukushima Prefecture, Japan. \\ 3 Suetsugi resident, Iwaki, Fukushima Prefecture, Japan. \\ ${ }^{4}$ Suetsugi, Our Home Town, Iwaki, Fukushima Prefecture, Japan. \\ ${ }^{5}$ Radiation consultant at Suetsugi, Iwaki, Fukushima Prefecture, Japan. \\ ${ }^{6}$ Fukushima Medical University, Fukushima City, Japan. \\ ${ }^{7}$ Fukushima Prefectural Centre for Environmental Creation, Miharu town, Fukushima Prefecture, Japan.
}

Received: 15 June 2020 / Accepted: 9 July 2020

\begin{abstract}
The article presents the different stages of the co-expertise process, which took place in the community of Suetsugi located about $30 \mathrm{~km}$ South from the Fukushima nuclear power plant, to improve radiological protection and the living conditions of the residents. The originality of the process lies in the fact that it was initiated and led by residents of the community with the help of local leaders and volunteer experts. It was also followed regularly by some members of the ICRP. The first part of the article recalls the general characteristics of the co-expertise process for post-nuclear accident management. The second part presents the different stages of the process that took place in the community of Suetsugi. The third part draws some lessons from the experience, which has significantly contributed to enriching the formalisation of the co-expertise process in particular with regard to the recovery of social trust and the role and attitude of experts during the recovery phase after a nuclear accident.
\end{abstract}

Keywords: nuclear power accident / recovery phase / co-expertise process / stakeholder involvement / Ethos in Fukushima

\section{Introduction}

The Suetsugi community is located on the seashore $27-$ $28 \mathrm{~km}$ away South from the Fukushima Daiichi Nuclear Power Plant (FDNPP) and $20 \mathrm{~km}$ North from Iwaki City (Fig. 1). The village covers only $7.4 \mathrm{~km}^{2}$. It is made of a valley with rice paddies surrounded by sharp hills covered by forest. The population in March 2011 just before the accident was 479 residents in 127 households of local old families sharing their activities between farming and working in the nearby cities of Iwaki and Futaba. Some of the residents were working for subcontracting companies from TEPCO. Some were retirees who came to settle there to enjoy the sea and the nearby mountains.

The tsunami that followed the Great East Coast Earthquake on March 11, 2011 hit Suetsugi, killed seven persons and

\footnotetext{
*Corresponding author: lochard@nagasaki-u.ac.jp

a Present address: 7, avenue Gallieni, 92160 Antony, France.
}

totally destroyed 27 houses and partially damaged 14 . The first hydrogen explosion at FDNPP occurred on March 12 and, on March 13, the municipality of Iwaki City sent a bus to Suetsugi and asked residents to "voluntarily" evacuate the village because Suetsugi was not designated as an mandatory evacuation area by the government. Many residents decided to leave. The government ordered on March 15 people residing in the 20 to $30 \mathrm{~km}$ area around the FDNPP to stay confined to their homes. Most of the people followed the order in general but one elderly woman who stayed did not stop her farm work during this period. The government lifted the sheltering order for Suetsugi on April 22. By the end of that month, the government asked residents of the 20 to $30 \mathrm{~km}$ area to stop producing the agricultural products voluntarily. As a result of this request, the time staying outside became less than before. Residents started to return to the village about one month after being evacuated. However, most of the young families with young children did not come back.

The months that followed were a difficult period for residents who returned their homes marked by growing 


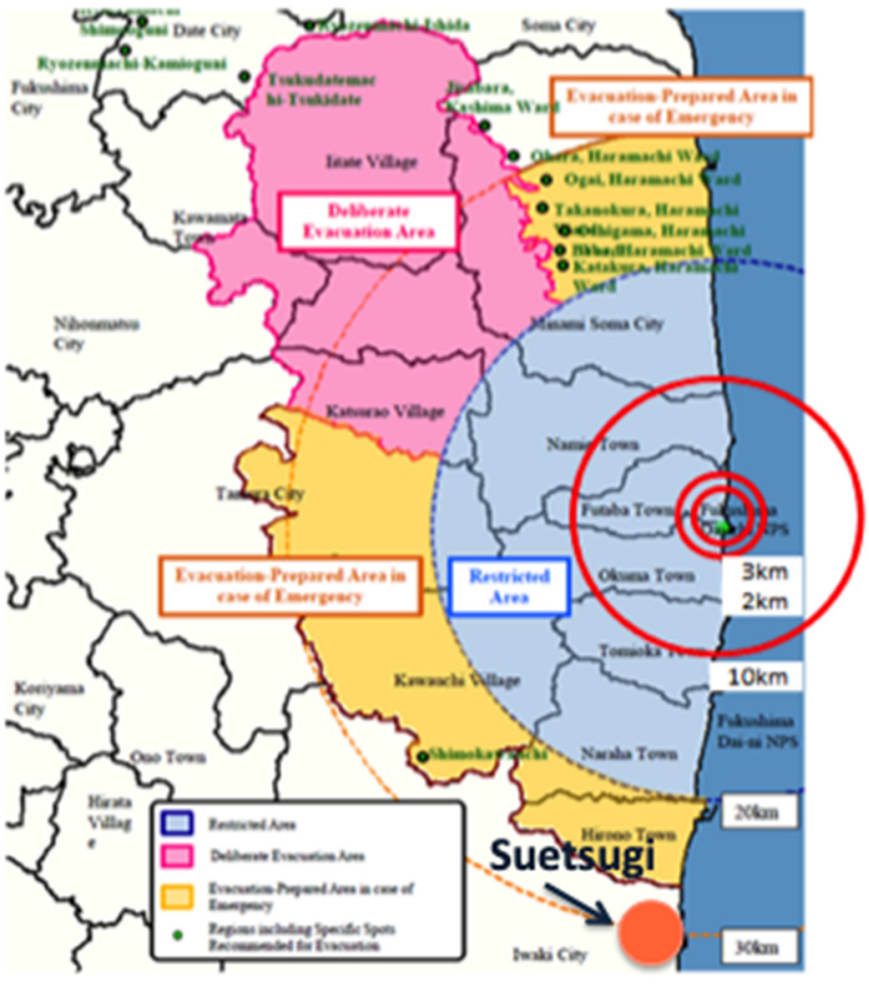

Fig. 1. Location of the Suetsugi community.

concern due to the presence of radioactivity in their environment for which they had no information and felt completely disarmed. This feeling was largely reinforced by the numerous reports in the media, most often incomprehensible and, moreover, contradictory. It is in this context that a resident of Suetsugi, took the initiative in summer 2011 to undertake with the help of other residents a campaign to measure radioactivity in the village. This event marked the start of what has become over the years an exemplary experience of cooperation between the Suetsugi community and volunteer experts who put themselves at their service.

This article presents in its first part the general features of the co-expertise process to improve the radiological protection and living conditions of affected people after a nuclear accident. The second part describes the different stages of the process, which took place in the Suetsugi community. The third part draws lessons from Suetsugi's experience, in particular with regard to the conditions and means for the practical implementation of the co-expertise process to address post-accident issues as well as in terms of the role and attitude of the experts involved and the restoration of social trust.

\section{The co-expertise process in post-nuclear accident management}

The notion of "co-expertise process" in the context of a post-nuclear accident situation emerged in the late 1990s in villages of Belarus affected by the Chernobyl accident in the context of the Ethos project aiming at involving the affected population and other stakeholders in the management of the radiological situation to improve both their protection and their living conditions (Hériard-Dubreuil et al., 1999). For three years, a multidisciplinary group of French experts worked with the villagers to resolve their main concerns: the restoration of the radiological quality of milk and meat produced in the village, the management of radioactive ashes resulting from the use of wood from surrounding forests to heat and cook in homes, the education of children and young people about the presence of radioactivity in the village, and the reduction of children internal contamination. The Ethos project has shown that it is feasible to involve directly local stakeholders in the improvement of their protection and their living conditions by relying on dialogue between experts and the affected people accompanied by measurements performed together to characterize the radiological situation. It has proven to be an effective means to break the feeling of loss of control of the affected people over the situation and to re-build trust progressively in authorities and experts. It also emphasised the importance for the experts to adopt a clear ethical position that respects the freedom of choice of people. The Ethos project was recognized by the United Nations Development Programme (UNDP) as an important model of how technical assistance can be used to promote community based programmes involving environmental education (UNDP, 2002).

The co-expertise process has been enriched, still in Belarus, in the framework of the International CORE Programme that followed in the early 2000s with the development of the so-called practical radiological protection culture to promote self-help protective actions among the population (Trafimchick, 2005). And, more recently, it has been refined through the experience gained in communities of Japan affected by the Fukushima accident (Ando, 2016a; Murakami et al., 2017; Takamura et al., 2018; Yasutaka et al., 2020).

From a methodological point of view, the co-expertise process is based on advances in the field of risk governance (Renn, 2008). Its practical implementation is a process consisting of four successive steps (Fig. 2).

The first step aims at establishing a dialogue between stakeholders in affected areas to identify their problems and the challenges. This can be initiated by authorities, experts or the affected people themselves. Through the dialogue, the latter ask, among others, questions about the radiation risk and this is an opportunity for experts to propose them working together to characterize the radiological situation in order to find ways to improve radiological protection and the living conditions in their communities.

The second step is to engage affected people in measurements of the radioactivity present in their living places as well as their individual exposures so that they understand when, where and how they are exposed in their day-to-day lives. By involving affected people in the measurement of radioactivity, it is possible to make visible what was invisible to them. To engage people in measurements should be progressively developed based on a comprehensive monitoring approach performed by the authorities and/or by affected people themselves (self-monitoring). By doing measurements themselves affected people regain gradually control over the radiological situation they are confronted with. To be meaningful, measurements should be done step by step from sources of exposures to the exposures received by people through the exposure pathways. Experience has shown that sharing measurement results to discuss the situation of the 


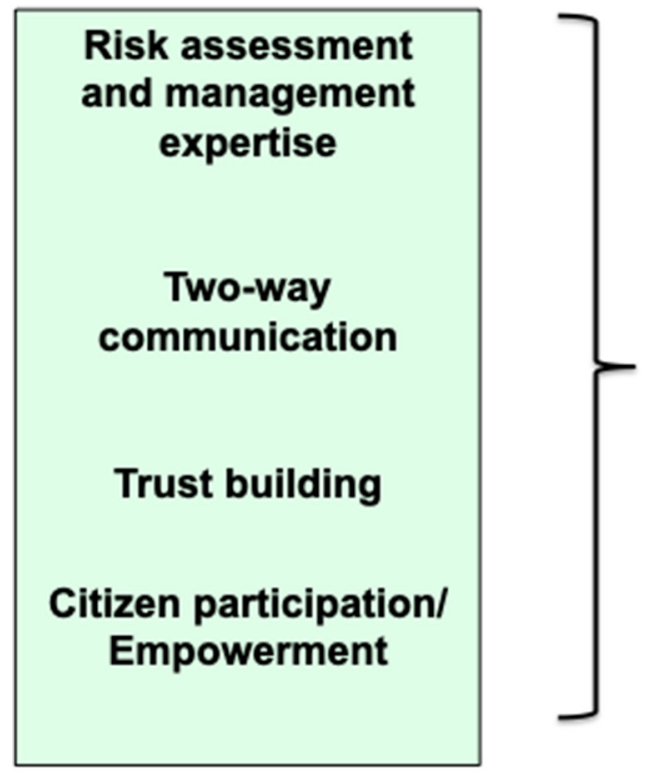

Fig. 2. The steps of the co-expertise process.

community is a powerful means to allow each individual to understand her/his own situation and to identify opportunities to improve her/his protection.

The third step is to identify and implement protective actions. By doing measurements together, it allows both affected people and experts to analyse and recognize the causes of individual's exposure and to provide information necessary to look for appropriate protective actions to reduce their individual exposures. And it allows identifying self-help protective actions implemented by the affected individuals as well as to review protective actions driven by the authorities with possibilities to adapt them if necessary. To achieve these self-help protective actions, the support of the public and/or private sectors (experts and authorities) is essential because it necessarily assemble technical and human resources. The experience gained from this process can also be helpful in reviewing relevant radiological standards. It has also shown that radiation measurements and then finding the solutions to control over the radiological situation lead people to balance their concern for their protection and their desire to enjoy life. The co-expertise process allows local stakeholders to make informed decisions for their own protection.

The fourth step is to organize citizen vigilance and to implement local projects with the support of experts. The objective is to set up a radiological monitoring program within the communities to promote the development of "citizen vigilance" on the radiological situation. This may result in projects implemented together by local people and experts to monitor specific aspects of the local radiological situation. It is also to accompany the development of local projects aiming at restoring sustainable livelihoods in the communities. Experience has shown that these projects in different fields (radiological protection, education, social activities, culture, memory, economy, etc.) should reflect the radiological situation and also the societal and economic conditions in the communities and should contribute to improving the wellbeing of individuals and the quality of the living together of the affected communities. The cooperation between stakeholders (local people, local authorities and professionals, private organizations...) with the support of experts is essential to implement these local projects effectively.

The co-expertise process is based on the recognition that to be meaningful for people exposed to radiation, knowledge in radiological protection have to be anchored in their daily reality to allow them to act to improve their future living conditions. This is only possible if they are directly involved in the process. This requires the mobilization of specific skills from the experts, suitable means of measuring radiation and the support of the authorities. It also takes time. The key to success is to put science and technology at the service of solving the concrete problems that people face as a consequence of the nuclear accident.

\section{The co-expertise process in Suetsugi}

The following sections present the progress of this process since the nuclear power plant accident in 2011 until the beginning of 2020 .

\subsection{The first citizen initiatives}

Very distressed by the deadlock in which he found himself after several months of forced inaction, Shinya Endo, a construction worker also farmer from Suetsugi, took the initiative to launch a measurement campaign to find out where and how much Suetsugi was contaminated. Beyond better understanding the local radiological situation, his objective was primarily to get an idea of the possibilities of resuming agricultural activities in the valley. During the winter of 2011 using materials borrowed free from Iwaki town hall and with financial support from the Suetsugi ward, he measured, with the help of a small group of community volunteers, the ambient dose rates throughout the valley and in particular in the rice fields and around the dwellings (Fig. 3). The group also took soil samples, which were measured by a private company in 


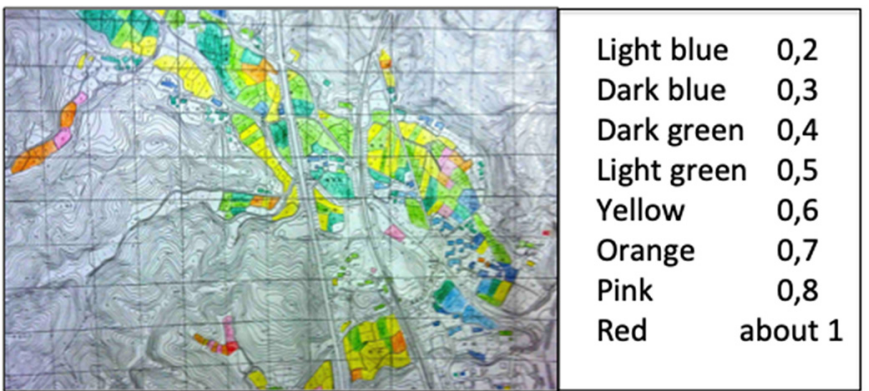

Fig. 3. An excerpt of the ambient dose rate map in winter 2011 in Suetsugi (microsievert per hour).

Iwaki that started measurements just after the accident. Overall, people in the community welcomed and supported the initiative and had confidence in the measurements. About half a dozen of them created solid connections and became the core members of the co-expertise process. Among them, was Hiroshi Takagi, who became a year later, the headman of Suetsugi and then helped the process a lot.

Based on the results, S. Endo drew up a map of the contamination of the valley, which revealed a contrasting situation between the different plots analysed. Not having the expertise to interpret the results, S. Endo contacted through a mutual friend Ms Ando, from the non-profit association "Ethos in Fukushima". She had already created a study group on the radiological situation in her village not far from Suetsugi. Analysis of the measurement results revealed relatively low levels of ambient dose rates and soil contaminations. Also, Ms Ando advised residents to undertake the measurement of individual exposure in order to make the link with the results of the local ambient dose rate measurements.

A first meeting with the residents to measure ambient dose rates and to discuss about the general situation in the village on March 30 and April 1, 2012 was organized with the support of Dr Makoto Miyazaki, a radiologist from the Fukushima Medical University (FMU). The latter joined in March 2012 voluntarily the process initiated at Suetsugi following an invitation from Ms Ando. It is interesting to note in passing that they first met on Twitter on the occasion of a meeting organized by Ms Ando concerning the situation in her village. It turned out that social media played an important role in the process that followed these first initiatives. The measurement of individual doses started in April 2012 with a dozen personal active dosimeters borrowed from a regional NGO involved in the post-accident activities of Fukushima. Six people initially wore the dosimeters for a period of three to four weeks. Ms Ando helped by Mr Kusumoto, a Suetsugi native living and working in Iwaki and Dr Miyazaki analysed the data.

\subsection{The dialogue with ICRP}

Ms Ando, who had been involved since February 2012 in the Fukushima Dialogue Initiative, took advantage of the third Dialogue meeting held in Date City to invite an ICRP delegation to visit Suetsugi and meet the residents (Ban, 2016; Lochard, 2016; Lochard et al., 2019). Several dozen of them and representatives of the media gathered at the Community House and they had the opportunity to express their concerns

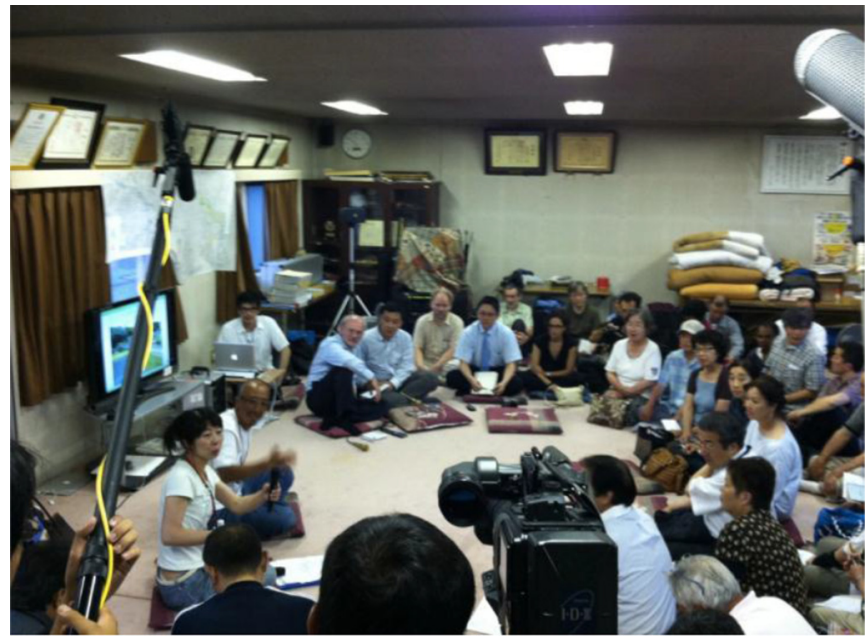

Fig. 4. The July 2012 meeting with ICRP in Suetsugi.

and ask many questions about the radiological situation in the village (Fig. 4). What is the risk in Suetsugi? Can our children come to visit us with their children? Can we eat the products from our gardens? Will I ever be able to resume my farming activities? How effective is the decontamination? There was a perceptible tension in the audience and even anger by some participants at the start of the meeting. But a constructive dialogue was gradually established.

Concerning the many questions on the risk, ICRP members explained that ultimately it depends for each person on where they lived, their daily activities and their lifestyle. Without having precise information on the radiological situation of the village, it was difficult for them to answer those questions. They advised participants to take steps to better understand where, when and how they were exposed. They also suggested establishing contact with experts to help them carry out the measurements and interpret the results.

Following this first visit, ICRP members regularly returned to Suetsugi. From July 2012 to summer 2019, members of the Commission met with the community 13 times. Each meeting was an opportunity for fruitful exchanges for both parties. Building on Belarus' experience in co-expertise, the residents were able to benefit from some useful advice from the lCRP members. These latter also took advantage of these visits to enrich their understanding of the mechanisms at work in the process. Residents of Suetsugi participated at the 7th ICRP dialogue meeting held in Iwaki in November 2013. On this occasion, the regular meeting members organised a round table discussion between the community and the members of the ICRP. Ms Ando moderated the debate.

\subsection{The decontamination and waste issues}

The decontamination of Suetsugi was organized by Iwaki City with the support of the Ministry of Environment of Japan. It started in December 2012 and finished in summer of 2013. Initially eagerly awaited by residents, this decontamination was complicated when it came to storing the contaminated waste on the territory of the community. Since the city of Iwaki owns a wastewater treatment plant in the Suetsugi ward away from the dwellings, it was decided after several meetings with 


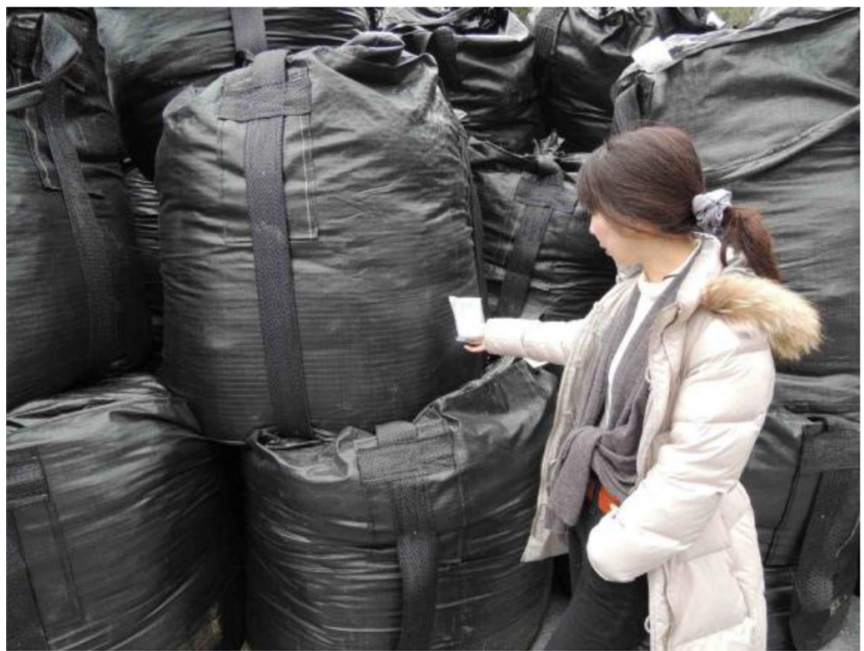

Fig. 5. Measurements by residents at the storage site.

the residents to store the waste near the plant temporarily. However, some residents were very concerned about the potential consequences of this decision on their health. Coincidentally, the ICRP's third visit in March 2013 took place when the decontamination work was already well advanced and the co-expertise process core members organized a visit to a decontamination site as well as the storage site. This was an opportunity for many residents to ask questions about the effectiveness of the decontamination works and on the risks associated with the storage site. Explanations about the design and operation of the storage site as well as on-site measurements about ambient dose rates showing that a few meters away from the bags of waste stacked on the site the dose rate was similar to that of the village gradually reassured the inhabitants (Fig. 5). During the debriefing session at the Community House, the ICRP members advised the participants to organize themselves the radiological monitoring of the site.

In autumn 2013, Iwaki City proposed to Suetsugi to also store the fly ashes from the city incinerator in the same place. Suetsugi accepted under the condition to receive support of their measurement activities from the city. The negotiation went for several months because Iwaki City was reluctant that residents make measurements themselves. Nevertheless, a member of the support team of the Cabinet Office of Japan for the Fukushima affairs finally came to Iwaki City Hall and negotiated directly with the executives of the municipality, which finally accepted paying a subsidy for the Suetsugi area. The source of this subsidy was the national budget for reconstruction projects in the nuclear disaster area, and in order to obtain this subsidy to the Suetsugi ward, Iwaki City needed to submit an application to the national government. It was extremely unusual for a government official to negotiate directly with a local municipality, and it was probably an exception in the post-accident recovery. In exchange for the reception of the ashes of the incinerator, the Suetsugi community received the financial support for D-Shuttle personal cumulative dosimeters recording dose per hour (Chiyoda Technol, 2018) and the surveillance of the site by independent experts: Dr Miyazaki from FMU and Prof Yoshiyuki Mizuno a professor of nuclear physics from Kyoto
Table 1. Results of the community whole body counter measurement campaigns of caesium.

\begin{tabular}{llll}
\hline & $\begin{array}{l}\text { Number of } \\
\text { individuals } \\
\text { measured }\end{array}$ & $\begin{array}{l}\text { Number of } \\
\text { individuals with } \\
\text { a detectable dose }\end{array}$ & Bq/body \\
\hline April 2013 & 124 & 8 & $420-1200$ \\
October 2013 & 39 & 0 & - \\
July 2014 & 39 & 0 & - \\
June 2015 & 45 & 1 & 510 \\
October 2015 & 31 & 0 & - \\
June 2016 & 30 & 0 & - \\
November 2016 & 25 & 1 & 320 \\
\hline
\end{tabular}

Women's University who engaged in dissemination of information on radiation risk after the accident (Mizuno and Ando, 2012).

Later on, ICRP members visited several times the waste storage site together with residents and had the opportunity to discuss and analyse with them the measurement results for both the decontamination waste and the fly ashes. It is to note that the latter have been reconditioned in safer containers at the request of the Suetsugi residents worried about the initial packaging. All this experience has shown that it is possible to involve residents concerned with the storage of low-level radioactive waste in the decision-making process concerning their future but also in their radiological monitoring. It is remarkable that after having assessed the risk associated with the storage of decontamination waste, the residents used their know-how to negotiate the reception of additional waste. Finally, all the decontamination waste had been transferred at the interim storage site in Futaba and Okuma and fly ash at the final disposal site in Tomioka by the beginning of 2020 .

\subsection{The whole body measurement campaigns}

In April 2013, the first whole body measurement campaign was organized by the Suetsugi community and Ethos in Fukushima with the support of Dr Makoto Miyazaki. 124 residents, young and old, men and women, took two chartered buses to go to Hirata central hospital in the Fukushima Prefecture about $60 \mathrm{~km}$ away from Suetsugi. At a meeting in May, they discussed the results of the campaign. Despite all sorts of lifestyles and eating habits radioactive caesium levels were below the detection limit in most people. It was a good surprise for the participants and in view of the results many of them, reassured, decided not to continue measurements (see Tab. 1).

The second campaign was organized in October 2013 and further campaigns continued about twice a year until the end of 2016. Results showed a drop in the number of detectable doses and the levels of contamination.

Despite the implementation of the internal contamination measurement campaign and its first rather encouraging results, residents remained reluctant to eat local products, particularly products from the forest, which were very popular before the accident. This persistent concern led the core groups to 


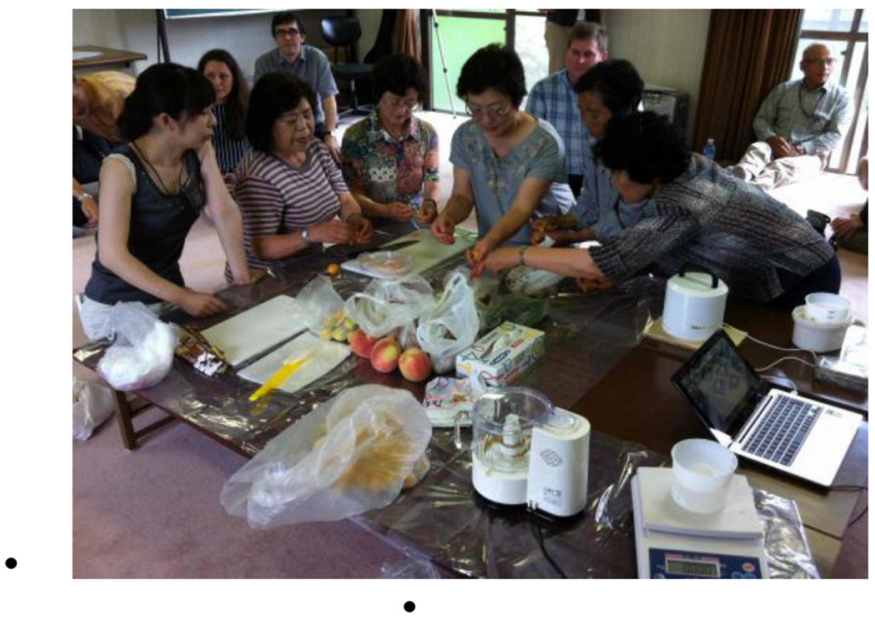

Fig. 6. Measurement of foodstuffs by residents in July 2013.

organise a session of measurements of food products from the gardens at the occasion of the fourth visit of ICRP members in July 2013 (Fig. 6). It was an opportunity to discuss the radiological quality of the products according to their provenance: shops, vegetable gardens, forest. Participants to the meeting asked questions about the interpretation of the values observed for potassium 40 and caesium 134 and 137 and why most results of whole body measurements were below the detection limit. They also inquired about the possible reasons for a few results being above the detection limit, the effectiveness of changing diet and the comparison with the results in Belarus provided by the ICRP members. The session ended in a heart-warming atmosphere with a meal prepared with the food products that had been measured.

A year later, at the occasion of their fifth visit in May 2014, ICRP members discussed once again the results of whole body measurement and the impact of individual choices related to diet. A resident lady explained that her husband had recently returned to the forest to pick up bamboo shoots that were his favourite. After measuring them and despite a moderate contamination, he nevertheless decided to eat them thus balancing his anxiety about the radiation and his desire to taste the fresh bamboo shoots, which he is very fond of. The ICRP members advised the lady to ask her husband to participate in the next whole body measurement campaign to verify the impact of the bamboo shoot season on his internal contamination. This anecdote made it possible to highlight the importance of individual measurements of radiation to restore self-confidence in affected people. Incidentally some participants referred to families who had not returned to Suetsugi because of potential problems at the NPP.

\subsection{The D-Shuttle experience}

In April 2014, Chiyoda Technol Corporation loaned 30 DShuttle dosimeters to the Suetsugi community. Neither the city of Iwaki nor the government was involved in this initiative. Residents carried out measurements through the intermediary of DrHayano, a nuclear physicist from the University of Tokyo, who became involved with the population of Fukushima Prefecture after the nuclear accident (Hayano, 2015). In January 2015, Iwaki City and the Suetsugi community officially signed an agreement and decided to lease the D-Shuttle for a fee (see Sect. 3.7). The contract was to rent 100 units for a year. Therefore, for the period from January 2015 to April 2016, a total of 115 units distributed to almost every household were in operation in Suetsugi. The measurements revealed exposure levels lower or slightly higher than $1 \mathrm{mSv}$ per year (Fig. 7).

This initiative had a considerable impact. Not only was each resident able to know her/his individual external exposure, but moreover thanks to the explanations of Dr Miyazaki she/he was able to understand on what occasions this exposure was received (Miyazaki, 2017). They discussed the results of the measurements together at meetings in the Community House, which allowed the community to gradually become aware of the role of lifestyles on the exposures and thus to establish a direct link with their daily actions (Ando, 2016b). From there the atmosphere within the community evolved, and the residents became more self-confidence and serene as evidenced by the testimony below (see Box 1).

\section{Box 1. A testimony of Masako Endo about the role of the individual measurements.}

Dr Miyazaki met with individual residents explaining the meaning of the data, answering their questions. It wasn't just measuring my external dose. His explanation using the graph was instrumental. Without the counseling, it's just another figure. I would not have been able to connect it to my life. After listening to him, I started to see the "link". Like, why my dose was low on a certain day little by little, I started to see my action and my dose were related (Ethos in Fukushima, 2018).

\subsection{Resumption of the full Suetsugi festival (spring 2014)}

The community of Suetsugi used to organise a festival every first weekend of April, the highlight of the ceremony taking place on the beach when a group of people supporting a portable shrine enters the sea. After the accident in March 2011, the annual festival was cancelled because Suetsugi was under the government sheltering order. However, already in spring 2012 the residents decided to resume the festival partly, skipping the beach ceremony because of the destruction caused by the tsunami. In April 2014, the resident were able to resume the full festival with the final ceremony on the beach (Fig. 8). This was an important step in rebuilding social ties in the community, although many of the young evacuees were not present. ICRP received an official invitation to participate to the April 2016 Suetsugi festival.

\subsection{The local project}

The idea of bringing together the various measurement activities developed so far in a coherent project has slowly taken shape over time. After a visit to Belarus organized in October 2011 on the sidelines of the ICRP dialogue initiative, Ms Ando realised that a key element in consolidating the involvement of residents would be the establishment of a food 


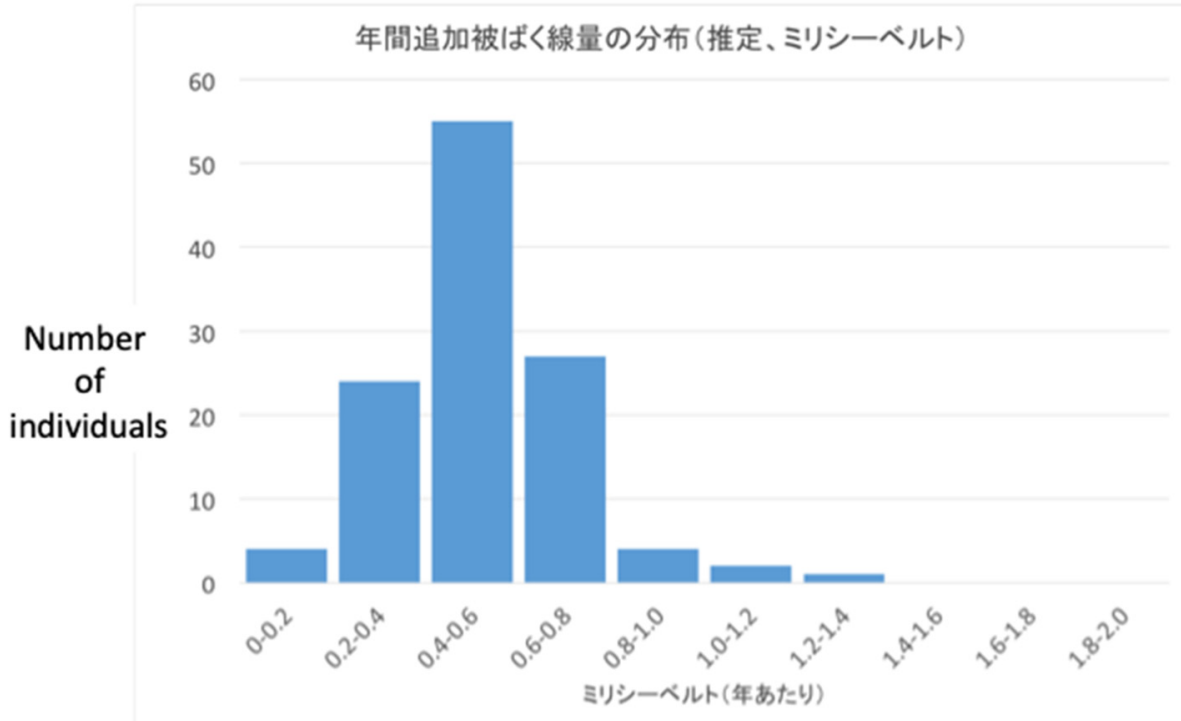

\section{Graph made by Dr Makoto Miyazaki, Fukushima Medical University}

\section{Borrowed from Ryoko Ando}

Fig. 7. The distribution of annual external individual effective doses of inhabitants of the Suetsugi community in 2015 (millisievert per year).

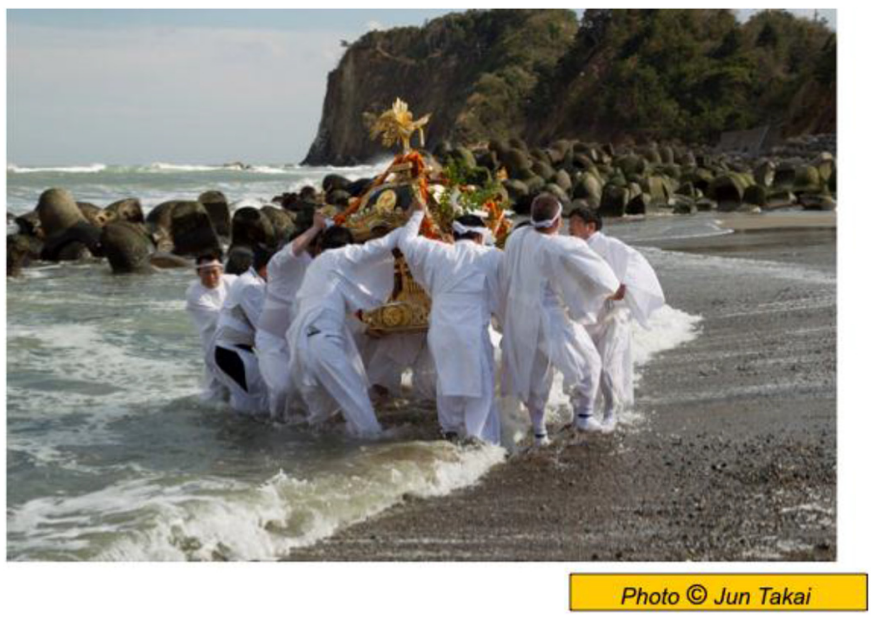

Fig. 8. The April 2014 Suetsugi festival.

measurement centre along the lines of the radiological quality control centres which had been established within the framework of the CORE program in the district of Bragin in Belarus (Bataille et al., 2008). The challenge was to find a room and a person to run the measurements, however remained difficult to implement without a sufficient budget.

When Suetsugi was invited to receive the fly ashes, Mr Takagi, who had since become the headman of the ward and had long wanted local government funds to measure individual exposures, jumped at the chance to negotiate a budget in return to accept the fly ashes. What started as voluntary activities got finally funding from January 2015 for a whole package, called the 'Suetsugi Project' including:

- the distribution of D-Shuttle dosimeters to the community; - a half-yearly whole body counter campaign;
- the support of a part-time counsellor in charge of measurements;

- weekly foodstuff measurement sessions at the community centre;

- the publication once every four months of a newsletter;

- the scientific and technical support from Fukushima Medical University (FMU) experts.

Thanks to this framework, residents could go once a week to the community centre made available to the project by the Mayor to measure their food products and speak with Ms Maiko Momma, a resident of Yotsukura near Suetsugi, hired as a consultant by the project. Her role was not only to carry out the measurements of the samples brought by the residents, but also to provide them with information on the radiological quality of the local products and to answer questions related to the external and internal exposures in Suetsugi (Fig. 9).

The newsletter, Suetsugi Dayori (Suetsugi News), was to share the measurement results and general information on the life of the community with all residents. Also, it was to keep contact with those who had left the community after the accident and who started a new life elsewhere. The newsletter was made entirely by the core group. Ms Momma and a man who also supported the writing of articles collected the material, and Ms Ando formatted it. To date, 15 newsletters have been published (Fig. 10).

The project was able to receive financial support from Iwaki City between January 2015 to March 2017 and from FMU between April 2018, and March 2020. Finding these supports was not easy, which costed a lot of time and energy. It is thanks to their obstinacy and the quality of their activities, recognized by many national and international experts, that the inhabitants of Suetsugi were finally able to benefit from support that met their wishes. 


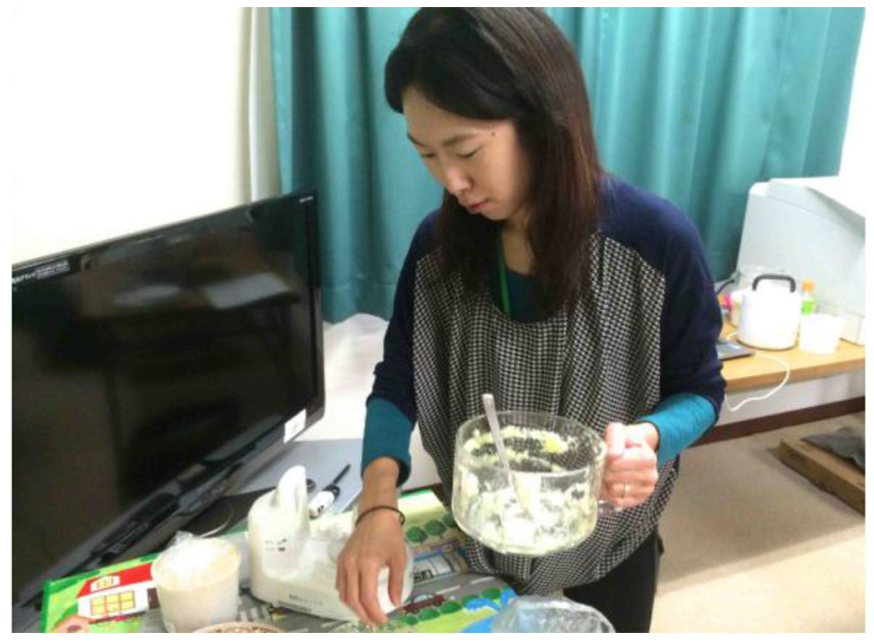

Fig. 9. The Suetsugi radiation consultant at work.

The leaders of the co-expertise process presented the "local project" to ICRP members during their seventh visit in December 2014. They were confident about the results of the negotiation with Iwaki City and their concerns were already one step further. They discussed the issue of the non-return of young couples with their children, the disparities in attitude between the various neighbouring communities, as well the impact of the presence of radioactivity on the behaviour and relations between inhabitants. They particularly emphasized the fact that the post-accident accident period had tightened ties in the community. The societal consequences of the accident thus took precedence over radiological concerns.

\subsection{The diffusion and transmission of experience}

Suetsugi's experience, very early relayed by the ICRP dialogue initiative in Fukushima, had a direct influence on the Japanese policy concerning the post Fukushima accident recovery process. Members of the support team of the Japan Office Cabinet for Fukushima who met Ms Ando at the ICRP dialogue meeting in July 2012 visited Suetsugi several times. The idea of the "local consultants" system to support the residents in the affected areas, which appeared in the "Basic policy on measures security and safety upon return", promulgated by the government in autumn 2013, was directly inspired by the activities undertaken by the community of Suetsugi (Arima, 2016). This system remains the most important for informing and advising people on radiological protection matters in areas where evacuation orders have been lifted.

Late 2014, a meeting was held in Tokyo with various representatives of ministries and authorities from towns and villages of the Hamadori region, the most affected by the radiation in the Fukushima Prefecture, Ms Ando and Dr Miyazaki presented the experience of Suetsugi, which was unknown to the other communities and also emphasized the importance of technical support from experts. In the following days, representatives of a neighbouring community visited Suetsugi to go deeper in the experience.

On two occasions, September 2016 and August 2017, the students of the Phoenix Leader Education Program for

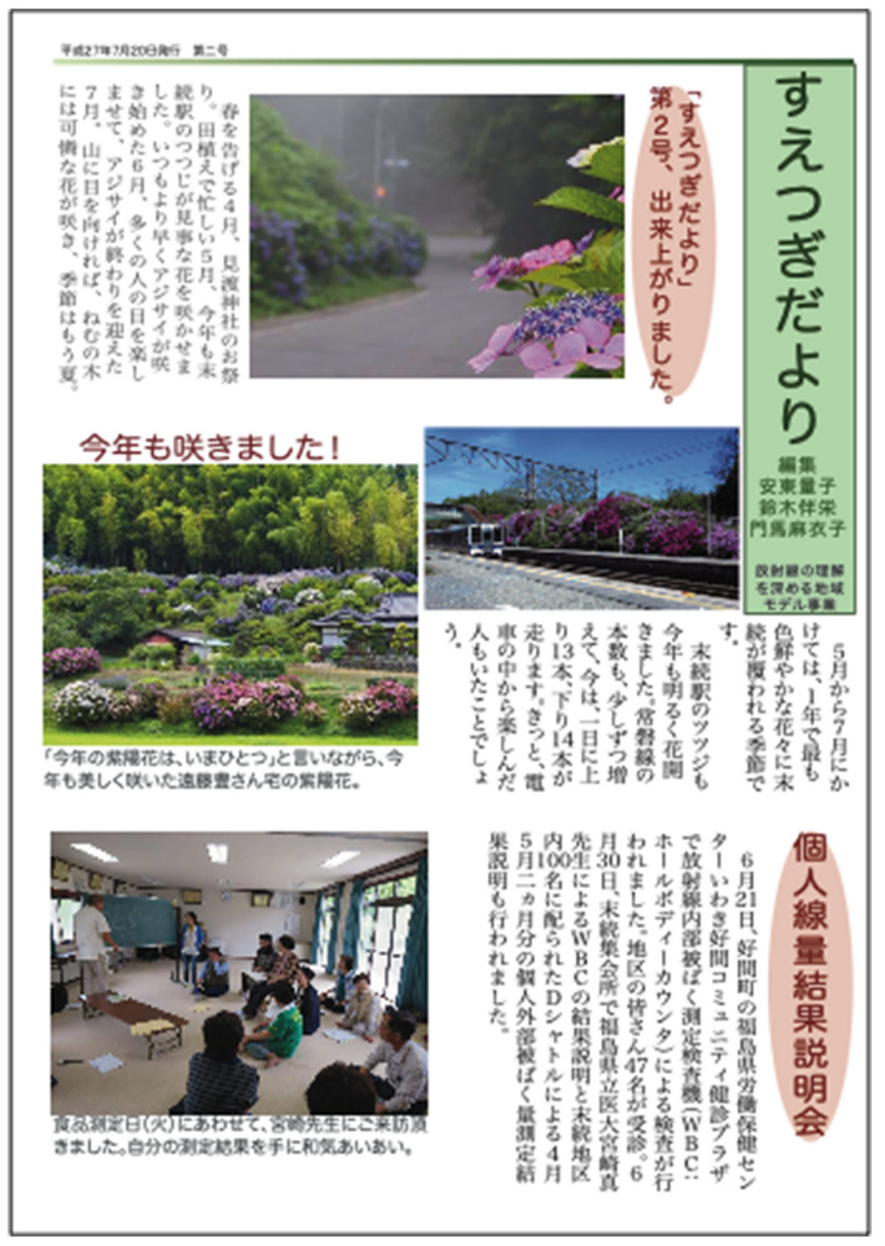

Fig. 10. The July 2015 of the Suetsugi Dayori.

Renaissance from Radiation Disaster of Hiroshima University carried out their field works as part of their course at Suetsugi. Welcomed at the Community House, the students listened to presentations on the events, which followed the tsunami and the nuclear accident as well as the radiological protection activities undertaken by the residents. Then, they visited the village including the new breakwater to protect the village against the risk of tsunamis and the radioactive waste storage site. Back, in the house, they attended a food contamination measurement session before taking part in a dialogue with residents who came to testify from their personal experiences. The residents of Suetsugi who participated in these fieldwork sessions provided many details in their explanations and obviously took great pleasure in sharing their collective experience with the students.

In time, participants in the co-expertise process felt the need to gather all the available information produced after the nuclear accident concerning the radiological situation as well as the testimony of residents on their paths towards the rehabilitation of their living conditions. Driven by the desire to transmit the experience of the community to present and future generations, the "Suetsugi Atlas project" launched in 2017, finally found funding from FMU. Coordinated by Ms Ando, the project benefits from the scientific and technical support of the experts involved in the co-expertise process. 


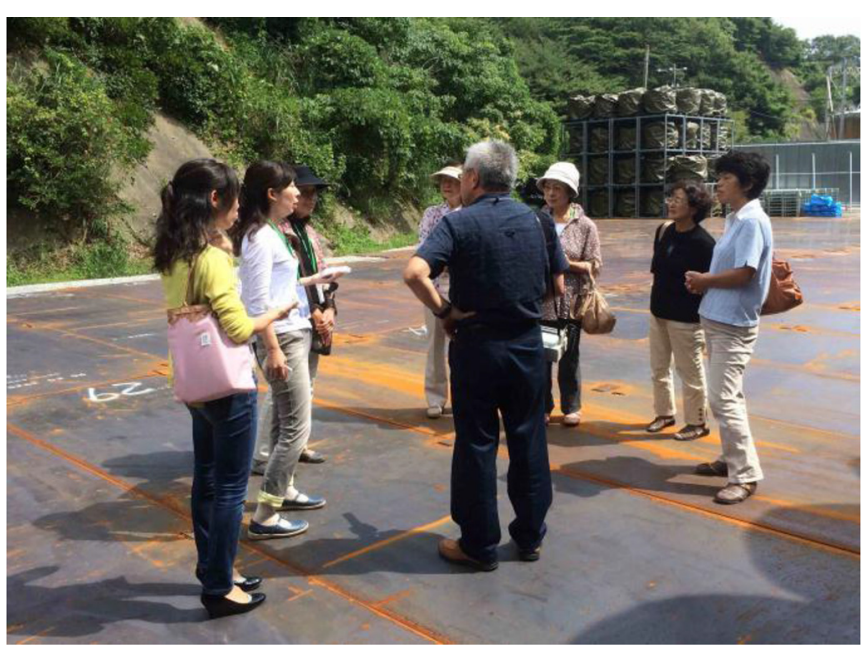

Fig. 11. Suetsugi residents doing their inspection tour of the decontamination waste disposal site of the village.

Beyond these initiatives, Suetsugi has become over time a popular place for many delegations of national and foreign experts concerned with better understanding the process of involvement and empowerment of the local population and the nature of its activities. So have succeeded in Suetsugi experts from the French Institute of Radioprotection and Nuclear Safety (IRSN) on several occasions including its General Director in July 2017, the Nuclear Protection Evaluation Centre (CEPN), the Norwegian Radiation and Nuclear Safety Authority (DSA) and the European "SHAMISEN project" focused on the improvement of medical and health surveillance after nuclear emergencies. Suetsugi has hosted several delegations from residents outside the Fukushima Prefecture as well as welcomed visits of high school students.

\subsection{Maintaining vigilance}

Beyond the concern of their individual exposures, the residents of Suetsugi also monitored the general evolution of the radiological situation of the whole community. This vigilance was first exercised following the storage of decontamination waste and the reception of fly ashes from the city of Iwaki. Small groups of villagers regularly visited the storage site to take measures to ensure the stability of the situation (Fig. 11). From the moment that the inhabitants were equipped with D-Shuttle dosimeters, these were used not only to assess the individual doses but also as a means of monitoring a possible rise in ambient radiation in the event of an incident perceived as always possible at the Fukushima power station. In fact, the residents had spontaneously supplemented the main function of the dosimeters for monitoring individual exposures with an alarm function.

Residents' commitment to exercising collective vigilance, combined with the monitoring of individual internal and external exposures and the radiological quality of the products, have gradually contributed to restoring social confidence within the community (Ando, 2018). Moreover, experts demonstrated their commitment to the community by making regular visit to Suetsugi. They confirmed the positive development of the local radiological situation, which also contributed to the restoration of social trust (Earle et al., 2007). As a resident expressed it very well in the video "Regaining confidence after the Fukushima accident: the story of the Suetsugi community" shot with the villagers: "That we are not forgotten, someone cares for us - that makes a difference. I'm not alone, there's someone I can trust... An actual human being, not something you read in a book. It's like, after everything, I'm no longer in fear. I won't use the word 'security'... it's more like a peace of mind" (Ethos in Fukushima, 2018).

Over time the number of residents measuring their products has gradually decreased. Some started relying on those who continued the measurements to stay informed about the situation, which alleviated their burden. Others, seeing the results of the measurements, began to question whether or not it was necessary to continue the monitoring system. Finally, in January 2020, the core group organized a meeting with the residents and the decision was made to end the scheme because they now know what to do and who to ask if something happens to them because food measurement is always available every day at the Iwaki City branch. It is undeniable that over time the residents of Suetsugi have acquired a practical radiological protection culture, which allows them not only to appreciate their radiological situation but also how to manage it for themselves and their love ones.

\section{Some lessons from the Suetsugi experience}

The co-expertise process described in this article is exemplary in more than one way. First of all, it was an initiative taken by the residents themselves. Suetsugi's experience shows that in the context of an open society where a lot of information is circulating, affected people can access means of measurement and recruit experts and professionals through social media. They can take ownership of the situation they face and find ways to overcome it. It is certain that the past experience of Belarus, especially the Ethos project, was a constant source of inspiration, as evidenced by the many questions posed to the members of the ICRP. From this point of view, all co-expertise processes must be documented and disseminated to help affected communities in the event of possible nuclear accidents in the future. Moreover, the residents of Suetsugi have shown a lot of creativity and independence in the way of implementing the co-expertise process. They have studied the measurement results together and decided on next steps sometimes with experts but also without them. In this approach, the role of local leaders like Ms Ando, MrEndo or Mr Takakgi was key to ensuring the continuity of the process.

Another lesson from Suetsugi's experience is that scientists, researchers and experts joined the process spontaneously and served the community over the long-term. Here again, the role of social media was decisive in "recruiting" goodwill. The process has also shown that to be credible, experts should not only master the scientific basis of radiation protection and its practical implementation and act transparently manner, but also demonstrate a lot of empathy and above all that they respect people's freedom of choice and remain faithful to their long-term commitment (Zoelzer and Zoelzer, 2020). These are necessary 
conditions for gradually restoring confidence among the affected people.

By its very nature based on dialogue and the appropriation of the radiological situation with which the affected people are confronted, a co-expertise process is an approach which proceeds in stages and which takes time. It is necessary to allow each participant time to assimilate the modalities and mechanisms by which he or she is exposed to the various radioactive sources present in the daily environment. Everyone has to gauge the importance of the exposures to which she/he is exposed and ultimately makes decisions about life choices. All this necessarily takes time.

The process of empowerment in which residents of Suetsugi acquired the practical culture of radiological protection was relatively similar in its development to that of the villages of Belarus (Lochard, 2013) in the late nineties. It was however more rapid because of the use of social media and the new generation of measurement means, in particular individual dosimeters for external exposures allowing a direct link with the daily activity of those who wear them. Not only the deployment of the co-expertise process, but also the provisions to ensure its sustainability were put in place fairly quickly.

Most notable, was the ability of the process, leaders to negotiate and ultimately secure financial support. Although Suetsugi's experience served as a model for national authorities, it did not spread as might be expected. The deployment of local consultants in other affected communities certainly played a decisive role with the population but did not allow the emergence of a commitment of the type of Suetsugi. In addition to the success of the approach, the Suetsugi experience has shown the limits of the public authorities in trusting the population to develop local projects aimed at improving their individual and collective protection and their living conditions.

Finally, it should be noted that, through the dialogues with ICRP members, the Suetsugi residents developed a rich narrative on their state of mind at the time of the accident and subsequently on the evolution of their feeling as the process unfolds. The testimonies in the video "Regaining confidence after the Fukushima accident: the story of the Suetsugi community" (Ethos in Fukushima, 2018), evidenced narratives on the days following the accident, the role of the measurements, the mechanisms for restoring confidence and the expectations for experts. These narratives shed profound and sometimes unprecedented light on the human dimension of a nuclear post-accident situation and on the driving forces of the co-expertise process.

\section{Conclusion}

It is undeniable that the testimonies and reflections of Suetsugi residents have contributed to a better understanding of the mechanisms at work in the co-expertise process after the nuclear accident.

Beyond confirming the key role of dialogue and the measurements of radiation to involve and empower residents to improve their protection and their living conditions, Suetsugi's experience has shown the importance for experts to adopt a clear ethical position while respecting the freedom of choice of the people (Schneider et al., 2019). It has also shown that the co-expertise process, whether initiated by locals or experts, can only unfold if authorities at all levels create the conditions to facilitate the process and support local initiatives and projects.

The Japanese experience, as before the Chernobyl one two decades before, has shown that the support of local initiatives and projects, which is a key for the rehabilitation of the living conditions, is an unresolved issue. Beyond the budgetary and equity aspects which are very real, there is a more general problem of governance on the part of the public authorities who do not see the point of entrusting to non-experts tasks which they think are of their exclusive jurisdiction. It is the difficulty, which has been very much highlighted by the coexpertise process carried out in Suetsugi. To cope with the high level of concern, the lack of knowledge and experience concerning the radiological risk, the general mistrust towards authorities and experts, and the great socio-economic complexity generated by the accident, past experience has clearly demonstrated the unavoidable need for a change in governance based on the decentralization of decisions and confidence in the capacity of those affected to take care of the problems of their community (Eikelmann and HériardDubreuil, 2016).

Despite the inevitable obstacles and difficulties, the Suetsugi's experience has confirmed that faced with the complexity and challenges of the situation resulting from a nuclear accident, all public and private actors and all stakeholders must commit to cooperate in responding to the problems and challenges of the affected areas. The coexpertise process, which can be considered a social innovation (Bodin, 2017), has proven to be effective in empowering those affected, helping them restore their well-being and the quality of "living together" in their communities and finally to regain their dignity.

The ICRP now recommends the co-expertise process for the management of post-nuclear accident situations. In recognition of their contribution to this process, on the occasion of the most recent visit of ICRP members to Suetsugi, the residents received a thank you plaque from the Comission in August 2019.

Acknowledgements. The authors wish to express their thanks to all the residents of Suetsugi. This article is dedicated to them in recognition of their invaluable contribution to the deepening of the co-expertise process. They also thank ICRP members Ohtsura Niwa, Chris Clement, Thierry Schneider and JeanFrançois Lecomte who, on several occasions visited Suetsugi, and constantly supported the experience.

\section{References}

Ando R. 2016a. Measuring, discussing, and living together: lessons from 4 years in Suetsugi. London: SAGE Publications. Ann. ICRP 45(1S): 75-83.

Ando R. 2016b. Reclaiming our lives in the wake of a nuclear plant accident. Clin. Oncol. 28: 275-276.

Ando R. 2018. Trust - what connects science to daily life. Health Phys. 115: 581-589. 
Arima M. 2016. Lifting of evacuation orders and subsequent efforts in Japan. Proceedings of the International workshop on the Fukushima Dialogue. Ann. ICRP 45(2S): 41-47.

Ban N. 2016. Japanese experience in stakeholder involvement: ICRP dialogue meetings. Radioprotection 51(HS1): S51-S53.

Bataille C, Crouail P, Lochard J. 2008. Rehabilitation of living conditions in the post-Chernobyl context: implementation of an inclusive radiation monitoring system in the Bragin District in Belarus. In: Proceedings of the International Conference on "Radioecology and Environmental Radioactivity" (part 2), Bergen, Norway, 15-20 June 2008, pp. 129-132.

Bodin Ö. 2017. Collaborative environmental governance: achieving collective action in social-ecological systems. Science 357: 659 .

Chiyoda Technol. 2018. Specifications of D-shuttle. Available from http://www.c-technol.co.jp/eng/e-dshuttle.

Ethos in Fukushima. 2018. Video: 'Regaining confidence after the Fukushima accident: the story of the Suetsugi community'. Available from https://youtu.be/L_ZhjixM6oM (also available in Japanese and French.

Earle T, Siegrist M, Gutscher H. 2007. Trust, risk perception and the TCC model of cooperation. In: Trust in cooperative risk management (M. Siegrist, T. Earle, H. Gutsher, Eds). London: Earthscan.

Eikelmann I, Hériard-Dubreuil G. 2016. Local populations facing long-term consequences of nuclear accidents: lessons learnt from Fukushima and Chernobyl. Available from http://www.mutadis. org/publication-local-populations-facing-long-term-consequen ces-of-nuclear-accidents-lessons-learnt-from-fukushima-andtchernobyl-2/.

Hayano R. 2015. Engaging with local stakeholders: some lessons from Fukushima for recovery. Ann. ICRP 44(Suppl.): 144-152.

Hériard-Dubreuil G, et al. 1999. Chernobyl post-accident management: the Ethos project. Health Phys. 77: 361-372.

Lochard J. 2013. Stakeholder engagement in regaining decent living conditions after Chernobyl. In: Social and ethical aspects of radiation risk management (D. Oughton, S.O. Hansson, Eds.), pp. 311-331. Radioactivity in the Environment, Vol. 9. Elsevier.

Lochard J. 2016. The genesis of the ICRP Dialogue meetings. Proceedings of the International workshop on the Fukushima Dialogue. Ann. ICRP 45(2S): 7-13.
Lochard J, Schneider T, Ando R, Niwa O, Clement C, Lecomte JF, Tada JI. 2019. An overview of the dialogue meetings initiated by ICRP in Japan after the Fukushima accident. Radioprotection 54 (2): 87-101. Available from https://www.radioprotection.org/ articles/radiopro/full_html/2019/02/radiopro190031/radio pro190031.html.

Miyazaki M. 2017. Using and explaining individual dosimetry data: case studies of four municipalities in Fukushima. Asia Pac. J. Public Health 29(2S): 110S-119S.

Mizuno Y, Ando R. 2012. "Fukushima-method" for local dissemination of information to recover living conditions after nuclear accident. J. Socio Inf. 5: 81-89.

Murakami M, et al. 2017. Communicating with residents about risks following the Fukushima nuclear accident. Asia Pac. J. Public Health. 29(2S): 74S-89S.

Renn O. 2008. Risk governance: coping with uncertainty in a complex world. Earthscan.

Schneider T, et al. 2019. The role of radiological protection experts in stakeholder involvement in the recovery phase of post-nuclear accident situations: some lessons from the Fukushima-Daïchi NPP accident. Radioprotection 54(4): 259-270.

Takamura N, Orita M, Taira Y, Fukushima Y, Yamashita S. 2018. Recovery from nuclear disaster in Fukushima: collaboration model. Radiat. Prot. Dosimetry 182(1): 49-52.

Trafimchick Z. 2005. The CORE programme in Belarus: a new approach to the rehabilitation of living conditions in contaminated areas. Vienna: Chernobyl Forum. Available from https://inis.iaea. org/collection/NCLCollectionStore/_Public/37/009/37009800. pdf.

UNDP/UNICEF. 2002. The human consequences of the Chernobyl nuclear accident: a strategy for recovery. New York: United National Development Programme.

Yasutaka T, Yumiko Kanaia Y, Momo Kuriharaa M, Kobayashib T, Kondohc A, Takahashib T, Kurodad Y. 2020. Dialogue, radiation measurements and other collaborative practices by experts and residents in the former evacuation areas of Fukushima: a case study in Yamakiya District, Kawamata Town. Radioprotection (in press).

Zoelzer F, Zoelzer N. 2020. Empathy as an ethical principle for environmental health. Sci. Total Environ. 705: 18 p.

Cite this article as: Lochard J, Ando R, Takagi H, Endo S, Momma M, Miyazaki M, Kuroda Y, Kusumoto T, Endo M, Endo S, Koyama Y. 2020. The post-nuclear accident co-expertise experience of the Suetsugi community in Fukushima Prefecture. Radioprotection 55(3): 225- 